Article

\title{
Socialization in the Neoliberal Academy of STEM Scholars: A Case Study of Negotiating Dispositions in an International Graduate Student in Entomology
}

\author{
Shakil Rabbi * and A. Suresh Canagarajah \\ Department of English, The Pennsylvania State University, University Park, PA 16802, USA; asc16@psu.edu \\ * Correspondence: shakilrabbi@psu.edu
}

Academic Editor: Ronald Strickland

Received: 14 February 2017; Accepted: 7 June 2017; Published: 10 June 2017

\begin{abstract}
This article examines how neoliberal orders of discourse shape the dispositions to academic literacies of an international graduate student in entomology. As this ideology of market logic consolidates its hegemony in universities of excellence and US culture at large, academic socialization and disciplinary activities increasingly aim to create scholarly dispositions and subjectivities that align with it. Such processes are further complicated by the backgrounds of international graduate students - an ever-larger proportion of graduate students in STEM who often hail from educational cultures significantly different from the U.S. Our analysis of an international graduate student's literacy practices in terms of motivations and outcomes shows that his literacies echo the dispositions pushed by neoliberal ideologies, but are not over-determined by them. Rather, as our case study illustrates, his socialization is a layered process, with ambiguous implications and strategic calculations making up literacies and disciplinary outcomes. We believe closely mapping such tensions in literacies and socialization processes increases humanities scholars' awareness both of the potential contradictions of educating international graduate students into the neoliberal model and of how the university can still be used to develop the dispositions needed to renegotiate the neoliberal order of discourse for more ethical and empowering purposes.
\end{abstract}

Keywords: dispositions; writing in the disciplines; neoliberalism; academic socialization; academic literacies; discourse analysis; STEM literacies

\section{Introduction}

Dispositions are receiving increasing attention in studies of academic socialization, especially those related to academic literacies in US universities (Canagarajah 2013a; Leonard 2014; Lee and Jenks 2016). As the mobility of scholars and texts intensifies and literate practices and genres are renegotiated in relation to changing conventions and contexts, literacy scholars have begun focusing on language awareness, literacy strategies, and rhetorical sensibilities that students-especially those with histories of mobility-treat as generative dispositions. While grammar and genre conventions cannot be transferred directly, dispositions are more mobile and adaptable; they can help students and scholars negotiate neoliberal cultural norms that often run counter to their own interests (Tardy 2009; Spack 1988; Canagarajah 2013b). Scholars have also realized that fostering critical awareness in the socialization process means recognizing the neoliberal context of culture in US higher education. Readings (Readings 1996) diagnosed this latter development well when he characterizes higher education institutions in the Anglophone west-and the U.S. in particular-as "universities of excellence," a social field organized in terms of sustaining a corporate bureaucracy (decisions about research and education are based on what is most marketable), commodifying learning, and financializing the educational process. A focus on dispositions can also help literacy scholars and 
educators consider how multilingual students and writers adapt to the distinct professional and specialized culture of the academic disciplines in US universities in ways that modify and build on the dispositions developed through histories of mobility across social and cultural contexts. By contrast, a traditional focus on language or genres would treat the need for cultural adjustment as one-sided and isolated to the academic socialization process.

Although socialization is, of course, not confined to institutional processing, this study focuses on the space of the academic discipline. Following the second-generation understanding of the term expressed in many classic studies of professional students, in this study "socialization in graduate school refers to the process through which individuals gain skills, knowledge, and values necessary for successful entry into professional career requiring an advanced level of specialized knowledge" (Weidman et al. 2001, p. 5). Literacy practices fall within the domain of knowledge and skills in this process, wherein graduate students learn the genres they need to perform the work of their disciplines, internalizing the epistemes, identities, and discourses seen as legitimate in their respective domains. In other words, in line with much of the work on the academic literacies model (see Street 2009), we see reading and writing, and the activities they are a part of, as social practices. This approach links elements of the disciplinary and writing situations (what some rhetorical genre scholars call the "context of situation" or "rhetorical situation") within which students are processed with the "context of the culture."

More specifically, our use of literacy as a social practice links knowledge and skills with dispositions directly and dynamically because it proposes that the latter do not exist independently from socialization. Rather a social practice approach to literacy argues that dispositions form in wide-ranging settings beyond writing and educational situations-settings that involve the challenge of renegotiating changing contexts and interests. In line with this work, we understand dispositions as similar to habitus, as defined by Pierre Bourdieu (1984). Along with Bourdieu, we argue that though shaped by social structures, dispositions are also generative and dialectical, having the potential to restructure social contexts. Because the social structures we inhabit are overlapping, layered, and conflicting, we believe dispositions are also ambiguous, inconsistent, and contradictory, necessitating reflective practice for achieving coherence precisely because we always possess them in sets or multiples.

Our study of socialization and literacy practices examines the social structure and culture of neoliberal academe-specifically how its "orders of discourse" shape a discipline (entomology). Our case study provides a snapshot of the socialization of an international graduate student by situating his literacy practices in terms of a generative disposition that negotiates the structure of the neoliberal culture of his discipline and US higher education in general. Our use of the term "order of discourse" is a heuristic to understand "some social domain [through] its discursive practices, and the relationships (of complementarity, inclusion/exclusion, opposition) between them" (Fairclough 1993, p. 135), be it in a specific discipline, or in the general culture of US higher education. Given its close connection to academic literacy practices research-which draws heavily from the work on critical language awareness and the need to foreground the ideological nature of literacy practices in neoliberal knowledge societies - we believe a discourse analysis framework informed by the works of critical discourse analysis (Fairclough 1993) and critical language awareness (Ivanič 1998) provides a coherent picture of academic socialization inculcating a complex relationship between literacy practices and dispositions in the graduate students.

To appreciate this complex relationship between dispositions and social practice, consider how the former are important to maintaining the neoliberal cultural status quo. Neoliberal orders of discourse enforce dispositions that define the neoliberal subject in US culture, where it is hegemonic Harvey (Harvey 2011). Even when acting in good faith, under the influence of neoliberalism, social and academic institutions socialize for the development of dispositions and motivations that will make for a successful economy and successful economic agents. The neoliberal order is built on the marketization of everything, including subjectivities. It relies on internalizing the discourse that success depends on 
individual effort and resources to market oneself successfully. As such, responsibility lies entirely with the individual, and higher education institutions should socialize people for dispositions that facilitate this goal of marketization of oneself in relation to constantly changing and diverse social conditions (Urciuoli and LaDousa 2013; Gershon 2011). Dispositions that favor neoliberalism include:

- Be enterprising (for developing oneself and one's resources for maximum material profit)

- Be creative (think outside the box to be strategic and innovative for marketing oneself and one's products)

- Develop a repertoire (so that one can adjust to any work condition or requirement as expected)

- Develop a portfolio of competencies and skills (that can relate to diverse market conditions)

- Undertake ongoing learning (so that one can retool oneself constantly for changing work conditions)

- Be competitive and strategic (positioning oneself as more relevant and profitable in any context)

- Focus on the soft skills of self-presentation and communicative competence (which help in marketing oneself and one's products effectively)

Complicating these dispositions are those that emerge through socialization into intimate families, homes, and communities. Such dispositions may have a slight detachment from the influences of dominant social ideologies. For example, the subject whose literacies we report below claims to have been socialized into dispositions of caring for others, developing a healthy work ethic, and moral values such as honesty and progressiveness. While these dispositions from different contexts can contradict the neoliberal status quo, certain others have ambivalent effects. Some that serve the interests of neoliberal material accumulation can also serve community interests and resist institutions. For example, being enterprising is useful for neoliberal subjects to address social needs without depending on institutions and governments for handouts. However, the same disposition can also account for creative and socially conscious projects that can lead to the empowerment of local communities, resisting marketization and profit making. Precisely because of their ambivalent effect, dispositions are sites of dialectical struggle in the socialization process. Explorations of how individuals negotiate these conflicts, what outcomes and literacy practices emerge, and where this struggle leads must be undertaken in a situated manner.

This article shows how the neoliberal orders of discourse in entomology shape the dispositions of an international graduate student. We narrate the ways in which he negotiates these dispositions through a tripartite system of motivations and outcomes: nature stuff (practices and outcomes of scientific interest); social stuff (practices and outcomes of community and environmental interest); and marketing stuff (practices and outcomes aligned with neoliberal interests). These three categories emerge from his own discourses. We also show that, in terms of outcomes, these practices are layered with ambiguous implications, which supports our argument that neoliberalism is not necessarily over-determining the socialization process, and humanities scholars can work with the affordances of the culture of the university of excellence to foster critical dispositions in this process.

\section{Data Collection and Analysis}

The case study presented here is based on multiple data points. Fifteen structured and semi-structured interviews related to general background information, academic socialization, and "talk around texts" based on stimulated recall methods (Lillis 2008; Gass and Mackey 2000) comprise the first data point. A collection of texts made up of all the extant drafts of a selection of his literacy practices related to a review article for publication, a grant proposal, or a PowerPoint for a presentation to beekeepers represent the second salient data point. Gunter's perspective on these literacy practices and activities were elicited through the "talk around text" interviews and analysis of embedded comments in the texts (Lillis and Curry 2006). Observations of disciplinary activities-written down in memos—and publicly available department literature represent the third point. 
We analyzed these data using grounded theory, as "flexible, heuristic strategies rather than formalistic procedures" (Charmaz 2000, p. 510), see (Clarke 2005), with a particular focus on pinpointing the elements of neoliberal discourse organizing Gunter's discipline and practices related to those discourses. We initially open coded our data, assigning the data points listed above a code related to the attitudes and beliefs of academic socialization. Next, we adopted focused coding to identify elements of what we saw as his socialization and literacy practices derived from neoliberal academe and related, on the one hand, to marketization and professionalization, and, on the other, to social and basic science research activities. At this stage, we also focus coded for aspects of dispositions we identified as motivations-the why of articulations (e.g., an intention or motivation to improve bee populations) - and outcomes - the what of articulations (e.g., a project to test the efficacy of pheromone treatment to reduce bee population losses over winter). We simultaneously axially coded these factors for triangulation purposes; we compared the codes of Gunter's dispositions with the discourses of the neoliberal academe to determine whether or not we were overlooking any salient patterns and themes in his perspectives and practices related to our focus on the influences of neoliberalism on academic socialization.

Finally, we selectively categorized our codes using "in vivo" codes, or his own words, to "preserve participants' meanings of their views and action in the coding itself" (Charmaz 2006, p. 55; see (Strauss and Corbin 1991)). In other words, we built up our theory grounded on our data in ways that backgrounded our own interpretations in the analytic codes. This process was, to state the obvious, recursive, as we interpreted and constantly compared the coded data with readings of relevant literature on the topic and emergent theorization during our discussions and throughout the writing process. For example, during our discussions we initially theorized that the motives of federal government initiatives to raise public awareness on pollinator health using university-based extensions systems aligned with the neoliberal outcomes of privatization (Harvey 2011); that is, the off-loading of the responsibility of ecological preservation from state actors onto private ones. At the same time, we recognized and prioritized Gunter's point that his participation in such public education projects was about the "right thing to do" (Gunter, Int., 30 May 2015). Taxpayers provided money to the program and, to Gunter, his work was about the social motive of giving something back to the taxpayers (i.e., social stuff).

Drawing theoretical metaphors from his own statements, our selective coding led us to identify Gunter's practices as governed by three dispositions related to his work as a graduate student: i.e., "nature stuff," "social stuff," and "marketing stuff." Nature stuff stands for what he defines in other places as "pure science." That is, practices contributing to evolutionary theory and understanding the laws of nature. Social stuff relates to "applied science," with references to protecting the environment, helping bee keepers and citizens with knowledge relevant for farming, and disseminating knowledge for environmental and social motives. "Marketing stuff" relates to "sales" metaphors he uses in his own discourses related to the socialization process of researching and publishing in terms of exchanging his knowledge for academic, personal, material, and institutional advancement.

In our presentation of the data below, we adopt a narrative structure to convey Gunter's literacy trajectory. We make use of the themes emerging from our coding to build Gunter's story. To understand the way he negotiates his research literacy requires that we situate our data analysis in temporal context-hence the adoption of a narrative structure.

We chose Gunter as typifying the overwhelming number of international scholars from non-western contexts who populate the STEM fields in the US. Beyond serving as graduate teachers and researchers, they go on to become professionals in diverse industries. Having been previously socialized into different work ethics in their families and schools in their home countries, they demonstrate the challenges of re-socialization into American cultures and ideologies during the transition to work and education in this country. Because of the relative sophistication Gunter exhibits in his literacy practices in the face of the different orders of discourse in neoliberal academe and in his discipline, our case study is certainly relevant to literacy scholars and educators. But its 
salience extends beyond these fields. He is also representative of the ever-increasing presence of international multilinguals in US higher education at the graduate level. In 2013/14 there were about 329, 584 international graduate students, up 6.0\% from 311,204 in 2012/13 (Davis 2016). International multilinguals represent an especially high percentage of students in STEM fields: over forty percent at the MA level and over fifty at the doctoral level (DeSilver 2015). Paralleling the institutional transformations resulting from increased access to higher education for working class students and minority students in years' prior, international students have become the exigent demographic category that US academe must socialize into its various disciplinary and discourse communities.

Scholars in writing studies have recognized the complexity of international student socialization processes and how internationals must make adjustments that domestic students simply do not have to make. Diana Belcher points out that while disciplinary competence in new members is uniformly lacking regardless of backgrounds, cultural competence vis-à-vis the US higher education context of culture can differ significantly between domestic and international students when the latter come from non-western contexts (Belcher 1994). Suresh Canagarajah (2002) (characterizes academia in non-western contexts as organized around a "civic consciousness," a culture of seeing disciplinary activities in terms of social relevance as much as disciplinary innovation and specialization (p. 189). Therefore, students coming into US universities from such contexts often have to rethink their research practices as they adjust to the university of excellence. They find it incongruous that disciplinary work does not have to be tied to the local communities they are a part of and this can lead to dis-investment in the roles they are required to acquire to succeed in academic and professional fields. Faculty and departments in charge of socializing such students often fail to see these culturally modulated understandings of being an academic or a researcher as meriting interventions, or simply do not account for the fact that even upon successful PhD socialization, international students might be going to countries where norms and expectations vary considerably from those in the US and an academic career is not organized around producing specialized esoteric knowledge (Weidman et al. 2001; Smith 1993; Ruetten 1998).

Gunter's literacies and developing dispositions show a socialization that negotiates these divergent needs in practice. Case study research and ethnographies are not generalizable by definition. Yet, ethnographic case studies can be used to represent instances of "ideals" through which researchers make sense of complexity (Weber 2015, pp. 89-93). Mary Lea and Brian Street say that this is the strength of such studies for research: they can show "how theoretical perspectives and principles manifest themselves in a given circumstance" of socialization (Lea and Street 1998, p. 4). Gunter's story can inform those of us in the humanities of the possibilities of working with researchers in the sciences, both in terms of better socializing this new majority demographic in the STEM disciplines and in identifying ways such situated actors can enact agency against the neoliberal orders of discourse through engagement in literacy practices. His story also foregrounds the question of how we can understand graduate socialization in ways that recognize the needs of international students who may want to stay networked to their home countries.

\section{Gunter and his Dispositions}

Gunter is a PhD student in entomology from Turkey. Gunter believes himself progressive and possessing a critical consciousness, and his story shows how international graduate students must adjust to the neoliberal orders of discourse as they are socialized into disciplines situated in US culture. Completing a MS and BS in Biology in Turkey, Gunter had not spent any time in the US prior to his doctoral work at a large R1 mid-Atlantic university; all his prior education and socialization, in other words, took place in a non-western cultural context. He is also an affiliated researcher with a center promoting pollinator health (from now on called $\mathrm{CPH}$ ), an interdisciplinary group whose director is his professor and advisor, Juliana (pseudonym). While this group is ostensibly a group that aims to conduct applied scientific work, its members are mostly engaged in laboratories that focus on basic science research. 
Describing the dispositions he brings from his socialization in his home and community in Turkey, Gunter stated: "As a person, I would call myself progressive, that is decent" (Int. 30 May 2015). Among other factors, he referenced his college education at a progressive university and upbringing in a liberal-minded family to explain this progressive disposition. He described his family thus: "We grew up with honest ${ }^{1}$ and my mother always said 'I'd love you even if you're a garbage man. Just do it right.' Our background was pretty unreligious. My parents were both members of the communist party of Turkey" (Int., 30 May 2015). In addition to his secular upbringing in a country that has seen an upsurge in religious fundamentalism, Gunter, a stated atheist, has probably also been influenced by his parents' Marxism. In addition, he described the university he and his wife attended in Turkey as "leftist": "I was able to go to [the best technical university in Turkey] because of that [because of his good grades] which is very leftist and a great school. I liked it a lot and got my BS and MS [in Biology] there" (Int., 30 May 2015).

In talking about his scholarly interests, Gunter communicated that his sensitivity to the social dimension of knowledge and social knowledge as such evolved through his socialization in pre-PhD experiences: "I was always better with structural analysis of nature stuff than social stuff. Later on I educated myself on the social stuff" (Int., 30 May 2015). In his discursive representations of disciplinary activities, Gunter distinguished between research for pure or abstract knowledge and research motivated by salience and benefits to society and ecology. By "nature stuff," he meant his interest in understanding the laws of nature, especially in inquiries related to evolution. He often referred to this as "pure science" in comparison to "applied science," which was what he referred to as "social stuff" and which glossed the application of his scientific work in terms of social purposes and implications. This "social stuff" included an interest in preserving environmental ecology and helping beekeepers (and the public generally through his research on bee pollination) with knowledge, and disseminating the knowledge gleaned from research to help farming communities. In the interviews, he suggested a leaning towards or an affective resonance with the social dimension of his work, an aspect of his disposition that would, presumably, always come into tension with the drive to invest in research excellence, material outcomes, and institutional success. Successful socialization in neoliberal academe would mean drawing on these dispositions in ways that could be measured and leveraged for additional gain.

Gunter repeated this distinction in framing the long-term goal of his PhD. He said: "My long-term goal is doing research in any capacity; it can be at a university, the USDA, or a private institution. My research goals are things that combine certain levels of biological approaches, starting from genetics to ecology, to behavior. I'm usually matching the bottom to the top in biology. I'm a strong supporter of the idea that there is a genetic basis of all the things we see around in the living world and most of my research is related to that" (Int., 30 May 2015). Here we see the dispositions of his discipline as somewhat layered. Although committed to research in evolutionary biology ("nature stuff"), he is also motivated by the desire to understand and contribute to ecology and behavioral science. The interest in matching the "bottom to the top" - that is, exploring the ecological and social relevance of genetics - characterizes his motivation to engage in research with social applications. This disposition to match population data to population behavior also aligns easily with work in public-oriented activities that can shape social behavior related to improving ecology.

Gunter demonstrates his commitment to this belief by exploring diverse forms of communication in his discipline (i.e., marketing stuff and social stuff), which he says is something picked up during his PhD education. He says: "Now I will say nobody cares if you have good data, you need to communicate it others. Five years ago [before being socialized into his discipline in the US] I would have said the opposite. Writing is a way of showing it to people. Good efficient writing is key. Oral presentations and videos are other ways... There is a trend now with the all of this interactive teaching

1 We present the interview data and excerpts from drafts with minimal editing in order to be faithful to the data. 
and stuff, and I think it's going to get bigger" (Int., 30 May 2015). Gunter is interested in translating his knowledge to others in creative and engaging ways. This disposition differs from the pressure to publish research articles in high impact factor journals. We will see that this disposition connects to the outcomes of "citizen science" (i.e., encouraging those outside the university to do research and produce useful knowledge). At the same time, this disposition also relates to "market stuff", since a continuous investment in the communication of knowledge can help his professional advancement by keeping his name out there.

Even as Gunter states that he sees the value in such non-traditional communicative practices, his literacy practices still accede to the normative needs of the formulaic academic genres. Asked about his preferences in writing, he said: "Unfortunately, if you let me go, I like to write a little more colorfully. Most of the time the feedback I get is about toning it down. I learned to deal with it. Since that is what is expected. I find it tasteless and dry. I get bored when I read my own things. And I'm sure everyone gets bored, but they like being bored. So we go with it. My research team is very fact based people. They want every sentence to be backed up" (Int., 30 May 2015). These statements demonstrate a tension between Gunter's preferences and institutional expectations, with the latter being prioritized. In other words, we see a disposition of going with the norms of the field, an adherence to what others in entomology prefer as a literacy practice because he believes he will be writing for an audience with similar preferences as a part of his long-term goal of "doing research in any capacity" (Int., 30 May 2015).

\section{The Orders of Discourse in Entomology}

Before we consider Gunter's literacy practices, we must first examine the order of discourse of his workplace and the discipline within which he has undergone socialization. Scholars in the STEM fields face unique pressures - academic and socioeconomic - resulting from the reorganization of higher education institutions into universities of excellence where academics are measured largely on the metrics of research and publishing. Such metrics define how scholars are marketed. Publications in high impact factor journals, obtaining research grants, and research prestige are the only measures of a scholar' worth and professional status (Brown 2015; Bok 2004).

Roger Geiger points out that academic research in the sciences has generally depended on extramural sources, such as federal agencies and private foundations, for funding, resulting in the "compartmentalized institutions [of the modern research university], penetrated to varying degrees and various parts by external influences" (Geiger 2004, p. 40). Rather than depending on funds from their academic department or university, scientists have to fund themselves. Their very jobs depend as much on securing highly competitive grants as on publishing research. This disciplinary order of discourse - i.e., grantsmanship - means a privileging of dispositions and professional styling that foreground self-management, being enterprising, and self-reliance, along with the ability to market oneself efficiently to multiple funding agencies and sources.

The professional pressures of the university of excellence, thus, regulate both the lives and work of individual scholars, and structure STEM into a neoliberal order of discourse. In order to position themselves strategically for funding, academic departments-like individual scholars-must continuously demonstrate their research excellence. This is done through annual reports that list citations and extramural funding secured — often seen by administrators as signaling disciplinary excellence - that are thereby prioritized over all other goals. In terms of literacy practices, writing research papers and grant proposals take priority. Based on individual member success with these texts, departments compare themselves with other academic units in the university and with departments in their own field in other universities to demonstrate their excellence. Derived from this institutional culture, their prestige and productivity is in turn leveraged for funding and access to other scarce material and social resources. These are the contexts into which graduate students must socialize themselves and to succeed they must effectively mediate their literacy practices. Graduate students 
rightly come to see their disciplines as institutional spaces as much as academic domains and in their evolving roles as professionals they must adjust to accommodate these imperatives.

\subsection{Discourses of Funding Imperatives}

Like most STEM departments at R-1 institutions, the Department of Entomology in which Gunter is pursuing his PhD work is substantially supported by extramural institutions and organizations. In an open letter to the department in 2011, the chairman of the department states that, faced with " $19 \%$ cut in state appropriations" and National Research Council benchmarks, the department had accrued more extraneous funding from non-state sources, reaching "\$11 million in new funding in FY 2011." As of 2012, their research portfolio of "active grants . . accounts for a total of $\$ 23,704,800$; with USDA (35\%), NSF (14\%), and NIH (28\%)" (College of Agricultural Sciences 2011). In line with much of what has been written on the matter, as state and federal institutions gradually roll back funding for higher education institutions, departments at Gunter's university seek resources from private organizations.

Juliana's lab, where Gunter works, certainly exhibits this reliance on extramural funding: 6 current projects are funded by the USDA as of the writing of this manuscript, with 2 projects pending USDA funding and 1 pending NSF funding. These projects are fundamental to the socialization of new researchers since different grants focus on different types of research, which is the primary process of apprenticing graduate students into the discipline as a professional domain. Consequently, the pressures of funding can be conflicting, as certain grants favor applied science (social stuff) and position an apprentice scholar for a different career trajectory. Gunter observes: "If you do USDA grants, you will mostly do application work" (Int., 30 September 2015). However, if someone is interested in working at a research-intensive university, such grants may not help much. Gunter states: "And so if I apply for a job that is research-intensive, someone will ask why, since I don't even have an NSF grant" (Int., 30 September 2015). Application-focused grants have the potential to help the community and ecology through application of scientific research. However, they are valued less in the context of faculty positions. For the latter, one must do theoretical work, funded by NSF-in other words, do nature stuff. Thus, the hierarchy of funding sources reflects the hierarchy of academic practices in the STEMs, with the "nature stuff" carrying greater institutional and intellectual prestige.

Since most of the extramural funding comes from federal agencies, agendas from the federal government loom large in the discipline. When the federal government initiated several efforts to reverse and restore bee population levels in 2014, entomology researchers, including Gunter's team, were quick to take part. Unlike previous interventions in ecological conservations, however, this recent initiative emphasizes non-governmental actors in preservation efforts. In a memorandum in 2014, the US President highlights the economic and environmental value of pollinators (e.g., Honeybees and Monarch butterflies), and explains that the federal government had established a task force to push private actors to protect pollinator population. He writes:

Given the breadth, severity, and persistence of pollinator losses, it is critical to expand Federal efforts and take new steps to reverse pollinator losses and help restore populations to healthy levels. These steps should include the development of new public-private partnerships and increased citizen engagement. (Obama 2014)

Although worthy social and ecological concerns motivate this initiative, it also demonstrates that the federal government is gradually shifting the responsibility for environmental preservation to private institutions and agents.

The federal task force report, National Strategy to Promote the Health of Honeybees and other Pollinators (2015), identifies education as a key tool to achieve these goals of protecting pollinator populations. In particular, it recommends that federal agencies continue to prioritize broader "efforts aimed at training the next generation of scientists and/or educating the public, as well as expanding the knowledge base with respect to pollinators and their environment" (Pollinator Health Task Force 2015, p. 23). To do this, it emphasizes the use of the extension 
systems-networks linking professional scientists in land-grant institutions with residents in 3000 counties/parishes to "translate science into formats that people use to improve their lives and/or livelihoods" (Coopperative Foundation 2015). The report says that the work of these institutions should be furthered through USDA funding and the development of "a national interactive website where [stakeholders] can share examples of research findings, success stories, best management practices and other ideas" (Pollinator Health Task Force 2015, p. 21).

Such emphases by the federal government pushes stewardship of the environment into the hands of private actors while the government remains silent on broader policy and structural interventions for ecological protection. This trend is consistent with neoliberal discourses and social practices that prefer actions by private actors over governmental interventions as the norm (Harvey 2011; Brown 2015). By contrast, earlier federal actions were often legislative and policy-driven. The establishment of the Environmental Protection Agency (EPA) in 1970 was possible because of the National Environmental Protection Act of 1969. Earlier still, the United States Forest Service (USFS), charged with conserving forests and other public lands, was established in 1905, also through a federal fiat. These were structural interventions at the governmental level. Universities and private actors were certainly encouraged to assist larger federal initiatives. But federal policy and legislative actions were seen as primary.

Despite potential alignments to neoliberalism, the emphasis on funding projects with an educational focus is an important development and is reflected in the work in Gunter's department. In particular, the $\mathrm{CPH}$ takes advantage of the funds and disciplinary activities such initiatives spur by, on the one hand, conducting research on pollinators and training of a new generation of scientists and, on the other, educating stakeholders and creating curriculum for K-12 science classrooms. Researchers and students in the department and the CPH are cross-appointed with the university's extension program to communicate scientific knowledge to non-academic audiences, taking advantage of federal funds for extension or education activities. In other words, the department participates in "social stuff" in ways that fuse academic research with community services.

A grant proposal written by Juliana and other members of her lab-including Gunter-evidences the influence of these federal initiatives on how members of the department practice the genre. The proposal emphasizes the ability of Juliana's lab to deliver messages to the public and stimulate discussions on important issues related to pollinator health and pollinator research. The grant argues that it will do this by making use of the CPH's outreach programs to reach numerous stakeholders. That is, the proposal is framed to highlight how the research findings will be disseminated through public education activities, and articulates this in a way that aligns with the federal initiative and represents the department as one that does "social stuff".

In another example, an editorial by Juliana and another researcher-who works for the United States Department of Agriculture-for a special issue of a journal on pollinator health mentions both the task force report and the presidential memorandum. It gives a nod to the "sweeping set of US federal policy recommendations" by the US Pollinator Task Force "generated in response to President Obama's presidential memorandum on pollinators" (Juliana and Author B 2015, p. 3) as the "exigence" for the activities represented in the journal. In short, the discourse foregrounds federal government initiatives as fundamentally important developments to the discipline and signals that such moves directly shape the norms of entomology, including in Gunter's own lab.

This normative pressure toward disseminating knowledge outside the academic/research communities comes with mixed motivations and cultivates complexly layered practices. While public awareness will spur community involvement in ecological domains, entomology academics are not purely motivated by these concerns. The research community may undertake these efforts to vie for federal grants earmarked for this purpose, as well as private funding, in order to sponsor their academic pursuits and to create knowledge related to "nature stuff." In other words, the funding mechanism's orders of discourse layer the social stuff, nature stuff, and marketing stuff. Writing grant proposals is a high-stakes activity often motivated by marketing stuff (i.e., obtaining funds.) But it is also layered as the funds might be reserved for social stuff, which scholars might multipurpose 
for science stuff as well. These interests can be accomplished only if they compete for funds by demonstrating an interest in those agendas.

\subsection{Discourses of Publishing Imperatives}

Another discursive norm Gunter and his department face is the publishing imperative. Important in academia regardless of domain, research publications are the means through which individual researchers and academic departments are measured, securing academic prestige, ranking, and branding. In this area, the department and Gunter's lab are well placed. A 2011 departmental report boasts that publications by department faculty and graduate students had "nearly doubled" from 47 in 2005 to 89 in 2009. The journals they published in included Nature and Science, two of the most prestigious and high-impact journals in academic publishing (College of Agricultural Sciences 2011).

A count of the labs in the department listing their publications on their websites shows a total of 169 publications from 2010 to 2015. Juliana's lab accounts for 80 of these publications and the CPH publication list adds another 65 to this number from 2010 to 2016. This prolific research output has bolstered the department's academic prestige. It has also filtered into the culture of the department's graduate socialization program, as Gunter's description of a departmental discussion of a graduate student publication requirement indicates:

... there was a retreat in the department when I first got here and the discussion was about the requirements of the program and if we should update it. Some principal investigators and professors were discussing whether we should have publication requirements, which we really don't have. The number was four, either published or accepted by the time of graduation-not that I submitted. That did not go through, but we can see another push in that direction in the future, depending on which faculty members we have. (Int., 9 February 2016)

It is significant that an R-I university treats publication outcomes as a prerequisite for graduate socialization. A prerequisite of 4 published articles for graduation suggests a focus on scholarly output and textual production rather than knowledge acquisition and role development as the main motives of socialization in the department. Though the department did not implement the requirement of four publications-for-graduation, Gunter believes it will likely be introduced again later.

Publishing is evidence of another element in the order of discourse. Though publications for pure science ("nature stuff") are clearly more prestigious, we can understand that scholars derive other literacy and communicative practices from the extension work and citizen science initiatives encouraged by funding agencies. We will see below that there are many nonacademic genres of writing (newsletters) and multimodal communication (i.e., PowerPoint presentations) entomology practices for knowledge dissemination purposes (i.e., "social stuff"). We must continue to recognize that academic socialization in a neoliberal context will organize academic genres in ways that put the imperative to become competent in ever more skills and disciplinary outcomes at the same time. We have to factor in how such low-stakes academic communication as conference presentations and workshops can facilitate ecological or scientific outcomes related to high-stakes genres. Gunter has to invest his time and energy strategically to frame his research and writing in relation to these competing interests of social stuff, nature stuff, or marketing stuff, drawing from and inculcating-i.e., strengthening some over others, creating entirely new ones-different dispositions.

\subsection{Implications for Graduate Socialization}

The norms of funding and publication presented above shape Gunter's socialization because they structure his department, his discipline, and STEM as an academic domain. The mentoring graduate students receive focuses on making them successful in publishing and grantsmanship and these concerns shape the knowledge and roles they develop. In other words, students are educated in a hierarchy of literacy practices that values competition as much as scientific or academic 
knowledge. This is not to ignore the ways in which less direct pressures, such as the policies, plans, and vision reviewed above also socialize them into dispositions of collaboration and problem-exploration, among others.

So crucial is external funding to the discipline that the department teaches the grant proposal genre as a required writing assignment in a mandatory course for its graduate students. The course, called "Critical Thinking and Professional Development," explicitly articulates the literacy requirements of the field in its description:

This required course for Entomology graduate students focuses on developing the professional skills needed for a successful career in basic or applied research. Major topics addressed include (i) effective scientific communication, (ii) the mechanisms of research funding and peer review, (iii) critical evaluation of scientific evidence and arguments, (iv) basic principles of study design, and (v) research ethics and effective collaboration ... The course emphasizes practical application of the material presented to students' own research. Over the course of the semester, each student reviews relevant literature and develops and refines a research proposal based on their own scientific interests. (Critical Thinking and Professional Development course description emphasis added)

Interestingly, this course functions as a disciplinary writing course that is not situated in English or other units in the language arts, as might be expected. Combining in-class lectures and literacy-based disciplinarian activities, ENT 522 introduces the basic and crucial genres in entomology to students and frames them as a part of "the professional skills needed for a successful career in basic and applied research." Of note is that the final assignment is a grant proposal, a genre falling under both the "scientific communication" and "mechanisms of research funding and peer review" topic. As a socialization text, the proposal is useful because it serves as an opportunity to signal disciplinary competence rhetorically; as Greg Myers reminds us, these texts are about persuading the readers/evaluators that "[the researcher] is able to do the work, and that the work is potentially interesting to one's audience of other researchers" (Myers 1990, p. 42). At the same time, these texts layer academic and marketing concerns ("nature stuff" and "marketing stuff") more explicitly than any other academic genre.

Students are socialized into these disciplinary expectations in more subtle ways through mentoring. Marketing discourses tacitly pervade interactions in entomology and are often foregrounded as legitimate ways to think about writing. As an example of the mentoring advice students receive, consider Juliana's embedded comment on an early draft of the review article we textually analyze in Section 5:

We will have to see how we decide to sell this review ... it might be just about overwintering behavior in general, in which case we will start the article by talking about ... suffer tremendous losses during the overwintering period, and thus we need to better learn about what regulates entrance, maintenance and exit from the overwintering state and what makes it successful, and how we can improve management practices to improve survival (kind of how we sold the USDA grant). This evolutionary stuff would come more at the end. If we decide to send this to some place like Apidologie, Journal of Apicultural Research, I think that is the approach we should take. I don't think we have enough data right now to really sell the hypothesis of the conserved evolutionary pathways for a review ... (Embedded Comment, draft 9 April 2014; emphasis added)

Notice how Juliana repeats the word "sell" three times in her advice, representing the genre as a discourse of marketization and framing it in terms of economic exchange. The use of this metaphor to understand the rhetorical situation indexes notions such as competition to publish, the material rewards that follow publication, and promoting authors and their research in the academic market place. The genre advice Juliana provides shapes Gunter's orientation in terms of framing the article 
("how we decide to sell this review" ... "kind of how we sold the USDA grant") and choosing the platform ("we decide to send this to some place like Apidologie, Jounal of Apicultural Research"). It has implications in terms of the development of the dispositions of being enterprising and competitive, especially in considering research and writing as an enterprise of marketing one's academic work.

\subsection{Uptake}

Before proceeding further, it is important to listen to Gunter's own perspectives on how he relates to the neoliberal orders of discourse presented above. What is his uptake of these norms as they seep down through instruction, mentoring, and policies? To a considerable extent, he is influenced by the marketing discourses ubiquitous in his discipline and US culture. In our interviews, Gunter regularly refers to disciplinary literacy practices and research using such discourses. Talking about a recent grant submission, he says: "The first one was different, but this time they bought it. ... We made it very clear that we did this for the wellbeing of the bees. Seriously, we are not an agricultural lab. My real interest is in evolutionary processes, how things came to be as they are now, how bees work and how they click. But we pitched it like we made it look like that we are doing it for the bees; we just shaped our research process" (Int., 2 September 2015; emphasis added). Almost tongue in cheek here, Gunter explains that he and his advisor repackaged their research interests to suit an application to an organization with ecological concerns. This repackaging worked and their proposal was bought. In other words, they shaped the genre to foreground ecological preservation and pollinator health as the primary focus. Metaphors like "pitched" evoke notions of sales, reiterating the connotations of the word bought and the situation as an act of marketing. Gunter seems to have internalized the marketing stuff. At the same time, his other statements-that he is interested in evolutionary processes and that they "made it look like that [they] were doing it for the bees"-also suggests that the genre is as much about utilizing the practices of marketing stuff and social stuff in pursuit of nature stuff.

Gunter's discourse therefore shows sensitivity to framing his research in different ways according to the priorities of different funding organizations. In other words, he responds to the differences in the genre's context and audience. This literacy practice shows a strategic disposition shaped by neoliberal norms. We can see in his discourses that Gunter has to learn to understand and approach his research and writing to get the best out of the market conditions of academia. He is developing an enterprising disposition in order to shape his work to meet different expectations and requirements. These are the dispositions that the neoliberal university aims to inculcate via academic socialization.

Gunter takes market conditions seriously for good reasons. Because graduate students now rely on research grants to support their studies, funding is a critical consideration for Gunter. As Gunter says about his own experience: "for the last three years, if I have to take an average of it, it is probably like 50:50 [writing wise and research wise]. That is because I did publish one [article] and submitted one [for review] and submitted 5 funding proposals" (Int., 16 February 2016). In a previously referenced interview, he explains his thinking about grants:

If you bring money, money is money. It doesn't really matter. In terms of CVs and career. It can matter, but the fact is that these aren't my projects. What I do will affect my applications. If you do USDA grants and I will mostly do applicable work. And so, if I apply for a job that is research-intensive, someone will ask why since I don't even have an NSF grant. These projects aren't my projects. Most people understand that. Whatever you get you work on, and that's pretty ok. Actually, since I got the SARE myself is better than working on ten NSF projects. Because it is mine rather than my PIs. (Int., 2 September 2015)

Based on this statement, it appears getting any money at all is the primary consideration, and one can afford to be discriminating only after that. This is the norm of the STEMs in US academe and a socialized member has to accept this fact. At the same time, Gunter admits his future career depends on what kind of grants he gets. To compete for a faculty position at an R1 university, he says he would need to signal competence through attachment to projects funded by organizations such as the NSF. 
However, he also believes his current grant, which is application-based ("social stuff") research, is still very valuable since he is the primary investigator. Thus, the discourse echoes neoliberal values, which privilege the disposition of marketing oneself. Given the reality of competing markets for grant money, Gunter must situate himself within that professional dynamic to land a job at an R1 institution.

This same marketing discourse also shapes Gunter's thinking regarding research articles versus review articles. In one of our interviews, he mulls over the dilemma that while the discipline places less value on review articles than research articles, review articles may generate more citations:

Depends, if you are applying for a position, your review articles are worthless, they don't care. But, a good review article gets millions of citations, so they each have their own ... A research article will not get as many citations as a good review article can get. That's one of those things. (Int., 16 February 2016)

Gunter thus reiterates this calculating disposition regarding his options for publishing as well. He rationalizes the utility of the review article for his purposes by thinking that a good review would generate more citations. This is the kind of thinking that will stand him in good stead in the neoliberal norm. Though we do not see him showing sensitivity to the tensions these dispositions might generate with the "progressive" dispositions he mentioned receiving from his family and his "leftist" university in Turkey, the tensions do play out in his literacy practice. His literacy practice shows more complexity and resistance than is evident in his own discourse on the profession. This is not especially surprising since socialization always layers multiple dispositions and roles, and Gunter's literacy practices are no different.

\section{Negotiating Orders of Discourse in Literacy Practices}

We now examine how Gunter negotiates these divergent discourses in literacy practices. The most obvious presumption would be that academic socialization is strictly functional and Gunter's socialization and literacy practices are over-determined by the neoliberal order of discourse elaborated above. Marc Bousquet's criticism of writing in the disciplines as a "turn[ing] away from critical theory and towards institutionally focused pragmatism, towards acceptance of market logic, and towards increased collaboration with a vocational and technical model of education" (Bousquet 2002, pp. 495-96) assumes as much. In Gunter's case, however, we can see that the picture is more complex in practice. The motivations and outcomes of his literacy practices-i.e., his investment in the process-in relation to his dispositions and academic socialization are layered.

\subsection{Journal Publication}

We first examine the practices related to Gunter's successful academic publication, for which he was the primary author and his PI, Juliana, and an extension specialist (a non-tenure track faculty position) were secondary authors. The text starts as a literature review for his dissertation. However, from the very beginning, Juliana suggests that Gunter be cognizant of publishing possibilities early on in the writing process of the text (discussed above) - articulating, in other words, the discourse of prioritizing publication activities. Such an opportunity opens up when Juliana is asked to serve as a guest editor for a special issue of a journal on insect science. Subsequently, she asks Gunter to write the review article for the journal. Gunter states that Juliana's invitation speeds up his writing:

Juliana herself was part of the journal, it was a special edition on honeybee health and our stuff fit into it. We have also been working on a review for our overwintering project basically, but I was lingering and I was slow and she said that there is this special issue and it will fit there perfectly, so let's get it done and get it in there. So, I then sped up the process, I work more on it, I tried to get it ready for that. (Int., 16 February 2016)

Juliana leverages the situation to socialize Gunter through a firsthand experience in the process of journal publication. In contrast to a pedagogical genre, this writing exercise carries high-stakes 
outcomes related to the orders of discourse of the discipline: a publication that can help the team in the competition for knowledge dissemination. Knowledge acquisition is only an early part of the socialization process, and Gunter, as a late stage graduate student-he is working on his dissertation at the time-should participate in disciplinary genres. The practice also tacitly reiterates the neoliberal discourse that research for its own sake has less value in the discipline as a profession than publications or disciplinary contributions (Bean).

This opportunity elicits more investment from Gunter in the literacy practice; he writes more intensely to meet publishing requirements and deadlines. Before, as he puts it, he was "lingering and [ ... ] slow." After the invitation, Gunter writes more productively; starting with a text approximately 3400 words in December 2014, he subsequently builds it up to approximately 4500 words—with 79 articles cited - in the draft that he submits for publication in March 2015 (he initially writes 12 distinct drafts over seven months and the text still listed six sections as needed to be worked out). Time matters in research competition. As Gunter himself notes in one of his interviews, he does not want someone else to scoop the findings of research he himself is doing or the ideas he is developing. In this, we see the discourses of marketing stuff both reinforcing and drawing from dispositions encouraged by the socialization process.

Yet even if this greater investment might have had marketing motivations, it is articulated in terms of "social" and "nature stuff." In some of the early drafts, Gunter is unsure whether to frame the article around "nature stuff" or "social stuff." As the text develops, he layers the scientific and the social strategically in the framing statements of his introduction, clarifying his conflicting motivations and outcomes in the genre. In the introductory paragraph of an early draft, Gunter foregrounds contributions to science:

Honey bee (Apis mellifera) colonies can withstand a wide spectrum of environmental conditions and inhabit tropical to temperate regions. Honey bees originated from in subtropical Africa (Ruttner 1987; Hepburn and Radloff 1998) and subsequently dispersed into temperate regions of Eurasia (Whitfield et al. 2006). With this habitat expansion, honey bees encountered a radically different environment with cold and long winters. These temperate honey bee populations evolved the behavioral and physiological adaptations to allow them survive the associated nutritional dearth and low temperatures. "Overwintering behavior" is characterized by a cessation of brood rearing, reduced individual activity, changes in endocrine profiles, increased nutrient stores, increased worker longevity, and maybe most remarkably formation of a thermoregulating cluster. Interestingly, tropical regions also have seasonal fluctuations in environmental conditions including periods of nutritional dearth as a result of extreme wet or dry seasons. Colonies of tropical honey bee populations also respond to such prolonged periods of unfavorable conditions by ceasing brood rearing. Though distinct environmental factors are operating, we hypothesize that temperate and tropical honey bees exhibit similar physiological changes during these dearth periods. (draft 9 April 2014, emphasis added)

As we can see from the final sentence, the thesis focuses on the finding that bees demonstrate similar physiological changes regardless of environmental contexts. It is a statement that relates to scientific knowledge.

In her comments, Juliana suggests that they focus on the social stuff because they lack experimental data that would substantiate the evolutionary claims (i.e., the "nature stuff"):

I just convinced myself that you should re-write the intro paragraph from the perspective of bee health, management, etc. And leave this part for later. Maybe we can say that what we learn about overwintering can also help management of bee populations in tropical regions. (comment 9 April 2014)

Taking this suggestion, Gunter develops the application side in the introduction. Though still undecided, he includes a second introductory paragraph with a note saying that the paragraph "is a 
template to understand what needs to be added/taken out" (comment 15 May 2014). The following is the alternate introductory paragraph:

Agricultural production of many key crops, including vegetables, fruits, and nuts largely depend on managed pollinators such as honey bees. In the last two decades there has been a dramatic increase in honey bee colony losses. Populations of honey bees experience dramatic losses over the winter, with beekeepers in the US losing an average of $30 \%$ of their colonies in surveys conducted from 2006 to 2011. Previous studies have suggested that levels of Varroa mites and viruses are strongly correlated with colony losses, but the effects of these factors on overwintering bees at the molecular and physiological level have not been well studied. Better understanding the mechanisms regulating entrance, maintenance, and exit from the overwintering state and what makes it successful will provide a critical advantage for the development of better practices to improve survival of honey bees especially in temperate regions with harsh winters. (draft 15 May 2014, emphasis added)

Gunter frames the article as an effort to develop better practices that will help bee farmers improve the survival of their bee-stocks. In keeping with this focus, Juliana suggests that Gunter update the reported numbers of bee losses based on the most recent research. In relation to a sentence stating reported bee losses, Juliana comments: "Can you look at the most recent BIP update? They have had survey results through 2014. Maybe revise and say, in ... " (comment 10 February 2015). Gunter does as she advises and checks the latest information from the "BIP update." Though this does not change the sentence about bee losses, it does lead to the incorporation of a 2015 publication to replace a 2012 publication. In other words, this revisions process strengthens a statement foregrounding discourse about "social stuff".

Not satisfied, Juliana later moves up a section—-penned by Gunter-from the conclusion. She suggests integrating this section immediately after the sentence about the reported losses:

Successful overwintering of honey bee colonies is critical in order to provide vital pollination services, especially for early spring-blooming crops such as almonds, apples and cherries. The February/March California bloom requires 1.7 of the 2.5 million US honey bee colonies to pollinate 860 thousand acres of almonds. Projected increases in almond production will place additional demand on honey bee colony rentals. This demand could be met, at least in part, by improved overwintering; a 10\% reduction in overwintering loss could provide an additional 250,000 colonies for early spring pollination. Efforts to reduce overwintering losses should focus on enhancing colony strength and food stores in fall, improving queen quality and protecting bees from Varroa mites, pathogens and pesticides.

Again, this statement foregrounds the social stuff in the text. Thus, collaboration with his PI augments Gunter's practice of the social. Being less aware of the disciplinary field, he may not have recognized independently that foregrounding the social in the genre would encourage more buy-in.

As they continue revising the manuscript, the co-authors prod Gunter to read more articles to pursue newly emerging questions. This literacy practice deepens the knowledge he acquires in significant ways. Eventually, this comes to be articulated as part of the review article's purpose-to fill extant knowledge gaps ("nature stuff") on the overwintering of honey bees. This can be seen in Gunter's eventual decision to eventually design a model (Figure 1) that explains the multi-factor causes and effects of seasonal changes in the bee colony: 


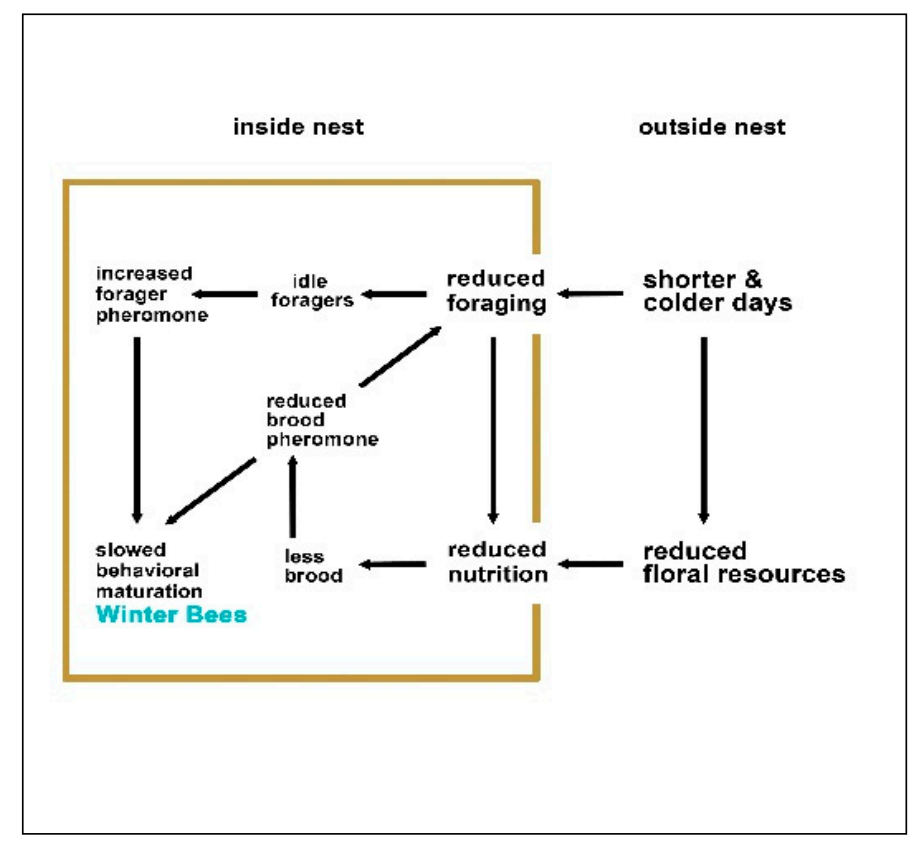

Figure 1. The model presented in Gunter's review article.

This model (Figure 1) enables Gunter to identify two pheromones-i.e., reduced brood pheromone and increased forager pheromone-as critical for explaining overwintering. This finding on physiological changes in bees helps him think about "the colonial life cycle in a more graphic way" (Int., 16 February 2016). In other words, it represents cognitive development in the socialization process.

Based on this evolving model, Gunter rewrites the introduction to reflect the scientific contribution that accompanies the research's practical applications. We can see how the final version for submission reflects the genre's diverse motivations in a layered and complex manner. The introduction starts by explaining to readers that reducing overwintering losses can help farmers of other agricultural products as well as beekeepers increase their produce (i.e., "social stuff"):

Honey bees (Apis mellifera) live in a wide geographic range occupying various climatic regions and facing different challenges in different parts of the world and times of the year [1]. Winter is the greatest challenge to the honey bee colonies in temperate regions. The honey bee is one of the few insect species that is adapted to survive winter conditions without becoming completely dormant, entering a distinct physiological and behavioral state [2]. Before Varroa and tracheal mites were introduced, overwintering colony losses were $\sim 10 \%$ [77]. However, an average loss of $\sim 30 \%$ winter loss was reported by the US beekeepers in surveys since 2006, compromising sustainability of commercial beekeeping operations $\left[3^{*}, 49\right]$. Honey bees provide critical pollination services for natural and agoecosystems world-wide. Successful overwintering of honey bee colonies is critical to meet the pollination needs of early spring-blooming crops such as almonds, apples and cherries. Indeed, the February/March California bloom requires 1.7 of the 2.5 million US honey bee colonies to pollinate 860 thousand acres of almonds, and this demand is projected to continue to rise. This demand could be met, at least in part, by improved overwintering: a $10 \%$ reduction in overwintering loss could provide an additional 250,000 colonies for early spring pollination.

The overwintering state of a honey bee colony is characterized by changes in the behavior and physiology of individual bees, including reduced individual activity, changes in endocrine profiles, increased nutrient stores and increased longevity, as well as changes at the colony level, including cessation of brood rearing and most remarkably, formation 
of a thermoregulating cluster. In non-temperate parts of the world, there are seasonal factors other than winter (i.e., dry, rainy, or hot periods with little forage available) that seem to trigger a broodless state followed by absconding of the nest site in search of a new one [78]. While certain aspects of the two life cycle events are similar (i.e., lack of forage, decreased/halted foraging, and cessation of brood rearing), overwintering provides a unique challenge for the honey bees to overcome extreme cold. (draft 28 May 2015, emphasis added)

The third paragraph establishes a gap in research, arguing that there has not been enough work done on physiological factors and this has made it challenging to develop better management strategies to reduce bee losses:

Previous studies have demonstrated that levels of Varroa mites, viruses, geographic location, and genotype are correlated with winter colony losses $[4,5,6,7,8,9]$. However, the effects of these factors on overwintering bees at the molecular, physiological and behavioral level have not been comprehensively studied, making it challenging to develop better management approaches to improve overwintering success. Here, we describe our existing knowledge of the environmental and physiological factors regulating entrance, maintenance, and exit from the overwintering state in honey bees in temperate regions. We then discuss factors associated with overwintering losses. Finally, we synthesize this information to provide recommendations for beekeepers to maximize overwintering survival and highlight areas of future investigation. (draft 28 February 2015, emphasis added)

In this manner, the findings on the nature stuff are presented as critical for solving the social and ecological problems of "better management approaches."

This textual analysis suggests that the diverse motivations for academic literacy do not have to be mutually exclusive, conflicting, or dysfunctional. For example, the discourses for excellence and marketization ordering the entomology department and Gunter's academic socialization do not have to negate motives related to social and ecological advancement. Nor do these factors have to background dispositions related to knowledge acquisition and research. Though the authors of this article initiate investment in the process because of the possibility of a successful publication, the practice leads to important scientific knowledge acquisition and disciplinary contribution. They are able to revise their framing of the paper finally to embed this scientific contribution in their submission. As literacy scholars, we must recognize that this practice of layering textually prevents academic literacies from being inculcated in Gunter in simplistic one-purpose ways; nothing is just "nature stuff" or "social stuff."

\subsection{Outcomes from Publication}

Whatever the motives for writing an article, its outcomes add a critical layer to the way neoliberal norms are negotiated. For instance, though an article might be written to compete for publication or advance scientific knowledge, it can still make useful contributions to ecology and society. In this section, we consider how Gunter perceives the outcomes of his publishing activity and how those outcomes manifest in a literacy practice for a grant proposal.

Though Gunter's revising strategies and embedded comments to his collaborators might suggest that he is driven by both a desire to produce scientific knowledge and publishing considerations (i.e., "nature stuff" and "marketing stuff," respectively), he shows an awareness of the other functions of the paper in a retrospective interview after publication. He mentions that the article "offer[s] a couple of different things. One of them was a theoretical functional model about how overwintering may be working... we also did talk about the colonial life cycle in a more graphic way. We provided some stuff. You know some students will read that somewhere and will take the figure and put it in the presentation, this kind of stuff. I am proud of it, it is good because it is useful, it's condensed and clear" (Int., 16 February 2016). In calling the model theoretical functional, Gunter shows an awareness of the 
twin functions of pure science and application. More importantly, he takes pride in the team's ability to offer readers something "useful" and "clear."

Thus, he acknowledges that extension experts who work directly with beekeepers might read the journal and the article. His suggestion that students will find the figure he developed helpful for their presentations and other academic needs reflects the influence of the progressive dispositions in Gunter's life and how he approaches the academic genre. He goes beyond the academic outcomes of his writing. He appreciates the value for students and beekeepers (via extension workers) that may not translate directly into research or material rewards for him. These workers would not be the professional researchers that a scientist would ideally be talking to in their scholarly genres. His satisfaction in this social contribution sounds sincere, and not suggestive of ulterior interests. Outcomes too are layered. The model Gunter's literature review develops is of additional socialization significance because he uses it for other outcomes. In particular, the model serves as the basis for a successful grant proposal to the Sustainable Agriculture Research and Education (SARE) program. The SARE, a private organization established to fund farmer-led research with an explicit focus on environmental sustainability, has recently begun funding graduate students for research with similar focus (Sustainable Agriculture Research and Education 2012).

Gunter mentions that the model representing the overwintering process encapsulates knowledge gleaned from "over hundred" articles he reviewed for the review article. The knowledge he acquired in the process helps him isolate two variables as potentially critical for overwintering of bees. They are the two types of pheromones: i.e., reduced brood and increased forager pheromones. This finding from the model turns out to have strategic value, as it provides a promising hypothesis that he can test and therefore proves a good fit for the grant proposal genre. (In representations of this model in presentations, Gunter often circles these two pheromones in red to show their importance.) Thus, the knowledge developed through writing helps win a grant proposal to test out the model for scientific theorization.

Considering that Gunter leveraged it into a successful national funding application, we can see the value of the review article in helping him generate a significant hypothesis. His previous 2014 SARE proposal did not have any statements about testing a model and using pheromonal treatments. The intervention plan in the 2014 proposal was also vague. In contrast, Gunter was able to theorize a new way of looking at overwintering mechanisms through the literacy practices of the review article, which he then realized could be studied through the type of project SARE might fund. The rest was about pitching the study for "a program [that] is very applied ... the committee are made up of also beekeepers. They expect it to be practical, sustainable, and relatable" (Int., 30 September 2015).

While somewhat altruistic, Gunter's motives for writing the grant proposal are layered. Although he has an interest in testing the model to develop his thesis regarding evolutionary theories on bees, the grant favors social contributions over creating scientific knowledge. Gunter says he was able to align his interest in understanding how bees evolved, how "they work and how they click", with the program's applied focus by "pitching it" to be "doing it for the bees, just shaping the research process" (Int., 30 September 2016). The socialization process-shaped by the discourse of funding imperatives-has taught Gunter to recognize that a testable model is useful to accrue grants earmarked for applied science. In the grant proposal, he explains that he would use the funds to "test this model" and subsequently operationalize it to improve overwintering survival through pheromone application. To this end, he states that the purpose of his project is to:

(1) determine the effect of fall applications of two honey bee pheromones (forager and brood pheromone) on the timing of winter bee production and the size of the winter bee population, (2) determine the effect of pheromone treatment on colony health and overwintering survival; (3) using the results from objectives 1 and 2, develop a pheromone treatment program to improve overwintering success, and partner with beekeepers to test this treatment program in real life conditions; and (4) disseminate the information from objectives 1, 2, and 3 to beekeepers and commercial bee breeders. (SARE draft 11 May 2015) 
We see here how Gunter's literacy practice layers the scientific and social/ecological in this genre, committing to the same framing he uses in the introduction of the review article. He argues that he has to test the significance of the two pheromones in order to develop a treatment program that can help farmers and have positive ecological outcomes. This framing suits both his interests. Testing out his hypothesis on the significance of the two pheromones would certainly help him in his ongoing dissertation work. Though that is a more distant outcome than the social stuff, he embeds it in his primary objective-developing a treatment program, partnering with beekeepers to test it in real life conditions, and then disseminating this information to breeders. As his references to "pitching" suggest, to some extent the social and ecological objectives are framed strategically to meet the needs of outcomes based in "marketing stuff" and "nature stuff."

\subsection{Extra-Academic Literacies}

While the motives exemplified above are largely products of the orders of discourse typical of an academic discipline (i.e., academic, personal, material) as an internally oriented community, Gunter also disseminates his knowledge to beekeepers even though they have little direct impact on his academic socialization. We will analyze such practices in this section. Though his dispositions related to the "social stuff" are more significant in motivating these literacies, they are not totally altruistic and community minded. They are partly motivated by the federal government's push to inform stakeholders and citizens about beekeeping concerns. In participating in these projects, Gunter and his colleagues demonstrate their social concern and also position themselves strategically for funds. At a larger scale of reference, these community and ecological contributions might feed into neoliberal interests as they encourage individual and community enterprise, reducing state/government intervention.

Consider first how the figure he developed bolsters his community contributions. The model is communicatively helpful because it synthesizes a great deal of complex information into a clear visual format. It draws information from research literature in the academic field and conveys it in a manner the layperson can understand. Presenting this complex scientific finding in the figure enables Gunter to use it easily when needed, whether talking to an academic audience or to beekeepers. "Science communication is important right now," Gunter says, explaining why they provided figures developed based on literature in the article and the grant proposal. "They're concise and artistic and very easy to understand" (Int., 16 February 2016). He also often uses the model in posters presented at professional beekeepers' meetings, and as an anchor in discussions regarding the aims of his work with lay and semi-academic audiences.

Gunter participates in his department's extension activities by giving workshop presentations at beekeepers' conferences. Beekeepers, generally skilled in managing bees, are ideally positioned to provide valuable scientific information. Gunter considers them "people [who] are well-intended and [are] this army of people who would like to do research on their own hives. I mean it's great, I would love to have that information rather than just tell them 'You suck, you shouldn't do science'" (Int., 22 April 2016). As opposed to academic practices that see laymen as unqualified for scientific research, Gunter and his lab members see beekeepers as resources for research and knowledge. That is, they see them as citizen scientists, participants in data-collection processes to expand "the knowledge base with respect to pollinators and their environment" (Pollinator Health Task Force 2015, pp. 22-23). Gunter values their knowledge and contribution to his research. We can see his progressive dispositions motivating such practice. It is important to recognize that citizen scientists are potential competitors for SARE grants and other ecologically minded funding organizations; the fact that Gunter is invested in developing their expertise despite this potential threat suggests that he is indeed "decent."

Researchers like Gunter recognize that trained researchers must facilitate the citizen science model. This is where he believes that he can make a contribution: providing workshops on data collection and experimental methods. His experiences interacting with beekeepers teach him that they want to do experiments, but lack scientific training and "fall into the pitfalls of experimental design that everyone 
would fall into. They don't standardize their treatment, they don't have controls, they have small samples" (Int., 22 April 2016). In other words, they generate findings that do not pass the reliability and validity tests for legitimate scientific data.

To educate them, Gunter adopts a communicative approach, involving a repertoire of language and rhetorical codes he develops just for this specific purpose. Rather than presenting data and explaining it in disciplinary terms, his literacy practices with beekeepers rely on humor and visuals. In a workshop he calls "Science 101 for Beekeepers," organized by extension workers and hosted by a university in Wyoming, his presentation demystifies who is a scientist, describes citizen science, talks about when the citizen science method is appropriate, and provides a successful example of citizen science. He also explains the fundamentals of scientific data collection. He paraphrases his workshop thus:

So what does a scientist have to have? You have to keep it simple, have a control, got to have a large data set. Large enough. You need good data so that data quality should be okay. You should focus on repetition so that it won't be useless. I then open up on those points. (Int. 22 April 2016)

A collection of slides (Figure 2) used in the workshop show literacies that avoid jargon and focus on translating technical concepts. The visual aids, unlike those typically presented at academic conferences, are comprised mainly of pictures and cartoons. This is not academic literacy, but popular science. In the slide about "Repetition and Stats," for example, Gunter uses a cartoon that depicts a father reading a bedtime story to his daughter to explain that single experiments might provide anomalous results and ascertaining whether the results are fact or coincidence requires repetition.
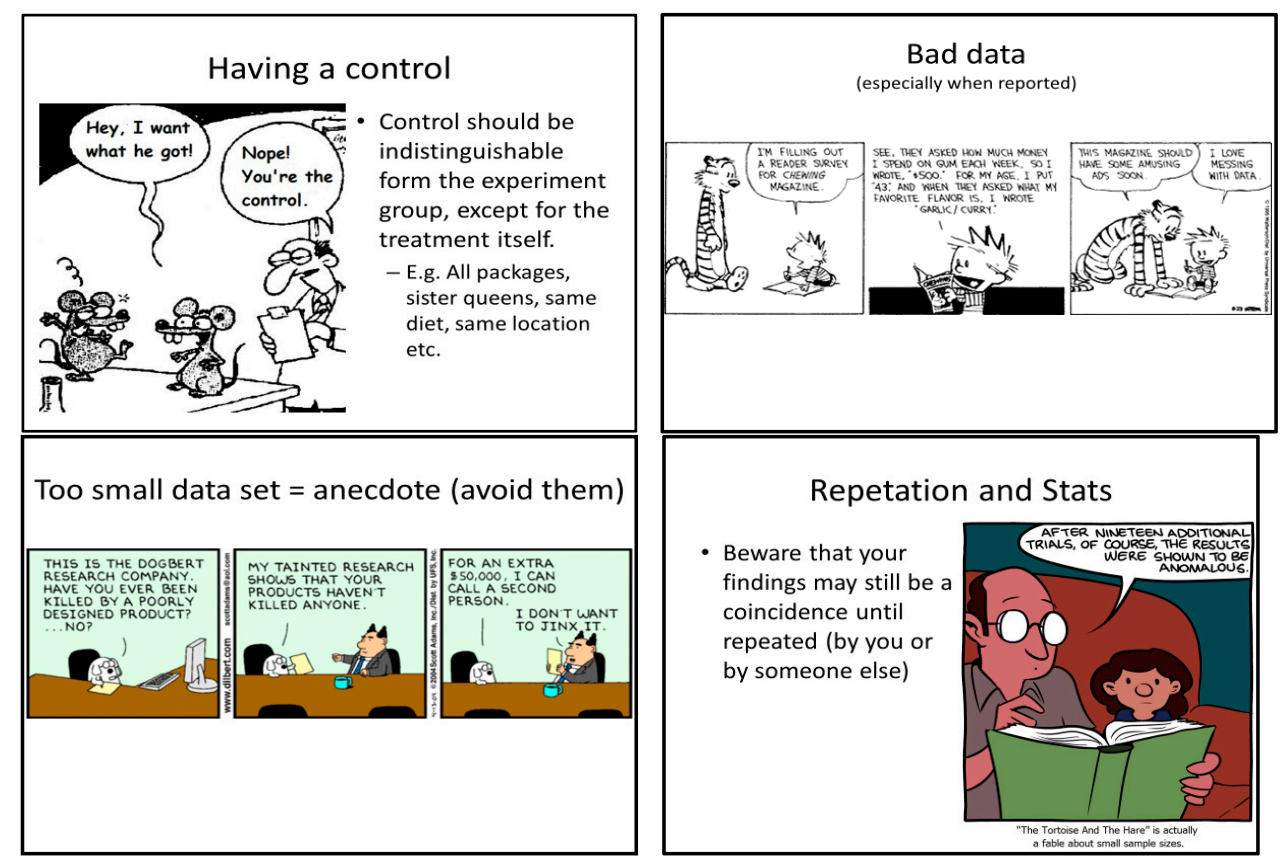

Figure 2. Four cartoons used as presentation slides in Science 101 for Beekeepers. Each cartoon represents a separate slide, which we have combined for presentation purposes.

In addition to these literacy activities, Gunter has produced plays to popularize his knowledge in other contexts. In an interview, he explains: "I do a lot of outreach genres. When you go to schools and go to public events, different age groups and talk to them about your research and about insects. My friend and I developed a play, but it was a child's play. It's short. I did that for a class, an outreach seminar. I would do it anyway. I'm open. I like it" (Int., 30 May 2015). Genres such as these are about speaking to groups of non-academics. In other words, similar to the work Gunter 
does with citizen scientists, these activities educate the extra-academic community about the scientific method with a focus on beekeeping and pollinator experimentation. They aim to develop the base of knowledge vis-a-vis pollinator losses so that they can preserve environmental ecology and increase their production with practices that deny specialization and academic esotericism.

In addition to this worthy social outcome, Gunter suggests that these practices may derive from his progressive dispositions. He recognizes that they will not contribute directly to academic recognition and/or revenue generation in entomology. Yet, Gunter participates in them enthusiastically and capably. His emphasis on "anyway" suggests that though he does not derive direct academic or material rewards, he would still engage in these activities. He says he does so because he both enjoys it and it is the right thing to do. Gunter says: "It's the right thing to do because I get money from the taxpayer in our program and so we need to give back. I also like it. It's a human audience and not robots like we face in academia. They are genuinely invested... if I present to beekeepers, I get emotional feedback. I like that. It turns into more of a two-way communication. People sometimes get pissed at you, sometimes they say great. It's normal human interaction" (Int. 11 November 2016). We can see that he is motivated by a sense of the "social stuff." He values the social interactions involved in this activity. Based on our observations of Gunter and his department engaging in discussions in multiple non-academic communities, we believe it would behoove scholars in the humanities to also actively participate in public discourse and work with school educators to ensure that our values of humanism and critical questioning continue to be represented in extra-academic domains.

In other interviews, Gunter explains how these outreach and community activities counteract the anxieties and stresses of working in the neoliberal university that overly prioritizes academic activity in its graduate students. Though he initially says that he gets little pleasure or creative stimulation from writing for publication, he is able to satisfy these needs through his practices in these other domains, and this effort lets him become "more comfortable with writing now, and enjoying it" (Gunter, Int., 30 May 2015). Perhaps such dissemination and community-oriented literacies assuage those dispositions that favor creativity and feelings, which we referenced in the beginning ("Unfortunately, if you let me go, I like to write a little more colorfully" (Int., 30 May 2015)), but which tend to become backgrounded in the academic socialization of graduate students.

Despite the motivations of the subject behind these extra-academic literacies, their outcomes too can be more contradictorily layered. Notwithstanding Gunter's good intentions, these activities sync with federal government initiatives to offload the responsibility for ecological preservation onto private actors, and facilitate activities wherein research is seen as endemically valuable and expanding the knowledge base and participants contributes to the process. In that sense, they contribute to the neoliberal status quo. Furthermore, these activities, which are designed to preserve the ecology and help citizen scientists, contribute to the general prestige of the lab and program. They therefore help the department vie for grants designed for ecological preservation and lay science. As we saw earlier, Gunter and his team compete for such grants and find them useful for scientific discoveries. At a broader scale of reference, then, such projects thus help him pursue his interests in "nature stuff."

\section{Discussion and Conclusions}

Our analysis finds that Gunter's motivations and outcomes are complexly layered. He comes to this program with avowed progressive dispositions and his academic socialization shapes those dispositions directly or indirectly influenced by the neoliberal orders of discourse in US academe. Yet our analysis also shows that his negotiation of academic literacies is not over-determined, despite the claims of many scholars that neoliberal orders of discourse allow little room for resistance or renegotiation (see Kubota 2014). Our case study suggests subtle ways researchers and scholars might renegotiate neoliberal expectations for more egalitarian, community-minded, ecological, and ethical disciplinary outcomes.

Without simplifying the complexities in our narrative, we can summarize the following dispositions manifested in the practices of Gunter's socialization. The successful publication of 
his journal article suggests that he was motivated by the pressure to publish competitively for academic prestige (i.e., "market stuff"). That the publication is aimed primarily for ecological preservation and citizen science (i.e., "social stuff") is only of secondary interest to Gunter and his co-authors. While framing the research and writing to achieve their primary aim, they stumble onto a significant physiological finding related to bee overwintering ("nature stuff") that further motivates them to publish this article. We do witness during this writing and academic socialization experience that Gunter develops new knowledge and much needed neoliberal dispositions, such as the ability to market his knowledge strategically, calculate his research options for maximum profit, and act competitively.

However, the outcomes of the article are diverse, and some of them directly satisfy his progressive dispositions. In Suresh Canagarajah's terms, the outcomes satisfy his "civic consciousness" (Canagarajah 2002, p. 189); they enable him, in his academic work, to draw on dispositions he might have developed during his earlier socialization in the Turkish context. The model of overwintering Gunter develops turns out to be very useful for citizen science (i.e., "social stuff"). We see him using this model effectively in knowledge dissemination for beekeepers. He also appreciates the value this figure has for students and other scholars.

Arguably, in a more community-minded context, academics and researchers would be expected to take on a public education and engagement role in their academic work, and it is likely that Gunter would have developed such a disposition to academic work prior to coming to the US. That logic underpins his comment that the money taxpayers pay to his program obligated the program to reciprocate in some way. The university he went to is funded by the state (as most postsecondary institutions have been in non-US contexts) and this meant that the university had to frame itself and its work in direct relation to the development of the community at large rather than individual disciplines and technical knowledge. Gunter imbibed such an ethos and brought it with him to his PhD work with the intention of keeping it going in his future work. Academic work in non-western contexts often means taking on the mantle of public intellectualism and Gunter's activities with citizen science keep him invested in such activities. In this way, his academic socialization continues; and he continues to develop literacy skills that could apply to academic work in international and less market-driven contexts.

Showing that graduate education in the US context can be modified to facilitate community-minded activities might be of relevance to international graduate students who intend to work in countries where academic work is not organized in the same way as the US disciplines. This point, which academic socialization scholars recognize, needs to be addressed in graduate student education (Weidman et al. 2001). Pedagogies of reflexivity are an ideal tool to enable this process. Humanities scholars are well positioned to advocate for such outcomes of academic socialization. Their scholarly work, after all, is well attuned to developing reflexivity and critical dispositions. Humanities scholars can work with the STEM disciplines so that they can teach for other ways and trajectories of disciplinary work, and develop socialization structures that prepare STEM students to contribute to local communities and fit into professions where the metrics of success are not blind to everything but research excellence. Engagement in the socialization of STEM scholars is bound to be of value to humanities too. While scholars in rhetoric, linguistics, and communication have an interest in theorizing notions such as neoliberalism, academic discourse, and scientific rhetoric, engaging closely with STEM scholars in their writing and socialization would introduce them to "real world" challenges that complicate their theorization and pedagogies constructively.

However, we also have to recognize that the outcomes identified above are at a more personal scale of consideration. If we expand our scale to more distant spatiotemporal scales, we can see neoliberal orders of discourse operating behind the observed outcomes. Gunter's knowledge dissemination puts environmental preservation into the hands of private actors, contributing to the trend of state disinvestment in these efforts. Thus, Gunter's activities indirectly satisfy some neoliberal ideologies and material expectations. Furthermore, on the individual level, these community and ecological 
activities may contribute to Gunter's own material and academic advancement. He uses them to test out his hypothesis on the importance of the two pheromones that could contribute to his research excellence and prestige in the long run. Also, these activities position him strategically for grants or publications related to citizen science by keeping his name out there, which, we show above, could be used to advance his interest in pure science.

The point of this narrative is not to argue that literacy scholars and education administrators should recognize how Gunter's progressive dispositions motivate him to resist and reconfigure neoliberalism. However, we do see subtle forms of renegotiation taking place and we recognize that this international student makes a particular cultural adjustment through his socialization into the neoliberal norms of US academe. To some extent, Gunter constructs some progressive spaces from within the neoliberal orders of discourse and the university of excellence because he has to if he wants to succeed in socializing into the discipline. That is, while marketing his knowledge and competing for material resources according to the neoliberal logic, Gunter develops knowledge that can contribute to ecological preservation and lay science to satisfy his own dispositions about what he thinks is "just do[ing] it right" (Int., 30 May 2015). We might say that he is investing in the neoliberal orders of discourse in his department and discipline by playing the game according to its rules in ways that do not lead to a disinvestment of his progressive interests. Perhaps we can say that he is also developing a habitus that might strategically resolve his diverse interests in the "social stuff," nature stuff," and "marketing stuff" to favor ecological and community outcomes.

This layering is good news, though it does still reproduce neoliberal norms. It testifies to the existence of spaces for progressive scholars to pursue altruistic, community-minded, and ecologically friendly research in academia. Bringing such negotiation strategies into the open can have far-reaching implications. We can make scholars in the STEM disciplines and humanities aware of the competing interests in their academic work and how they are interwoven in their research and writing at diverse scales. A continued sensitivity to orders of discourse will also help scholars and researchers understand how progressive interests at the local scale might have compromising implications at more global scales. Or how market constraints at the macro-order can be exploited for social and environmental good at the local level. This story also sheds light on the cultural adjustments being made by an international graduate student in the face of the neoliberal context of US academe-adjustments that enables him to continue in his socialization activities without disinvesting in the process by finding outlets for his progressive dispositions in work outside of academia.

This study provides promising insights for both humanities and STEM disciplines about the ideological adjustments international students might make if they are to succeed in US academe. It suggests that novice STEM scholars can adopt creative and critical scholarship even as they pursue the hard academic literacy practices required of socialization into research or professional disciplines. It is possible for humanities scholars to help STEM scholars negotiate the tensions between neoliberal dispositions and oppositional ethical dispositions as Gunter does. Humanities scholars in fields such as rhetoric, literacy, and languages can develop pedagogies and mentoring practices to socialize STEM students into the strategic negotiation practices that facilitate work in and outside of academia, recognizing that certain orders of discourse are cultural norms must be negotiated cautiously because they cannot be entirely rejected. Rhetorician Rebecca Dingo (2013) argues that we should adopt a "networking pedagogy" in academic literacies to make students aware of how different levels of social action and communication have geopolitical implications. Such pedagogies could help Gunter and other scholars in the STEM disciplines identify how to renegotiate the seemingly intractable neoliberal pressures for more ethical and empowering purposes in their academic literacies.

Acknowledgments: This study was made possible by the funding from the Migration Studies Project, Pennsylvania State University, and the Center for Global Studies, Pennsylvania State University.

Author Contributions: Shakil Rabbi was the lead author of the article; Shakil Rabbi collected the data; Shakil Rabbi and A. Suresh Canarajah analyzed the data; Shakil Rabbi and A. Suresh Canagarajah wrote the paper. 
Conflicts of Interest: The authors declare no conflicts of interest. The founding sponsors had no role in the design of the study; in the collection, analyses, or interpretation of data; in the writing of the manuscript, or in the decision to publish the results.

\section{References}

Belcher, Diana. 1994. The apprenticeship approach to advanced academic literacy: Graduate students and their mentors. English for Specific Purposes 13: 23-34. [CrossRef]

Bok, David. 2004. Universities in the Marketplace: The Commercialization of Higher Education. Princeton: Princeton University Press.

Bourdieu, Pierre. 1984. Distinction: A Social Critique of the Judgement of Taste. Cambridge: Harvard UP.

Bousquet, Marc. 2002. Composition as Management Science: Toward a University without a WPA. JAC 23: 493-526.

Brown, Wendy. 2015. Undoing the Demos: Neoliberalism's Stealth Revolution. New York: MIT Press.

Canagarajah, A. Suresh. 2002. A Geopolitics of Academic Writing. Pittsburgh: University of Pittsburgh Press.

Canagarajah, A. Suresh, ed. 2013a. Literacy as Translingual Practice: Between Communities and Classrooms. New York: Routledge.

Canagarajah, A. Suresh. 2013b. Translingual Practice: Global Englishes and Cosmopolitan Relations. New York: Routledge.

Charmaz, Kathy. 2000. Grounded Theory: Objectivist and Consructivist Methods. In Handbook of Qualitative Research. Edited by Norman K. Denzin and Yvonna Lincoln. Thousan Oaks: Sage Publications Inc.

Charmaz, Kathy. 2006. Constructing Grounded Theory. Thousand Oaks: Sage Publications.

Clarke, Adele E. 2005. Situational Analysis: Grounded Theory after the Postmodern Turn. Thousand Oaks: Sage Publications.

College of Agricultural Sciences. 2011. Penn State Entomology and our Future Outlook. Available online: http:/ / ento.psu.edu/news/2011/penn-state-entomology-and-our-future-outlook (accessed on 10 June 2017).

Coopperative Foundation. 2015. Coopperative Extension: Extending Knowledge, Changing Lives. Washington: Extension Foundation.

Davis, Todd M. 2016. Open Doors: Report on International Educational Exchange. New York: Institute of International Education.

DeSilver, Drew. 2015. Growth from Asia Drives Surge in US Foreign Students. Washington: Pew Research Center.

Dingo, Rebecca. 2013. Networking the Macro and Micro: Toward Transnational Literacy Practices. JAC 33: 529-52.

Fairclough, Norman. 1993. Critical Discourse Analysis and the Marketization of Public Discourse: The Universities. Discourse E Society 4: 133-68.

Gass, Susan M., and Alison Mackey. 2000. Stimulated Recall Methodology in Second language research. Mahwah: L. Erlbaum Associates.

Geiger, Roger L. 2004. Research \& Relevant Knowledge: American Research Universities since World War II. Transaction Series in Higher Education. New Brunswick: Transaction Publishers.

Gershon, Ilana. 2011. Neoliberal Agency. Current Anthropology 52: 537-55. [CrossRef]

Harvey, David. 2011. A Brief History of Neoliberalism. (Reprinted); Oxford: Oxford University Press.

Ivanič, Roz. 1998. Writing and Identity: The Discoursal Construction of Identity in Academic Writing. Philadelphia: John Benjamins.

Kubota, Ryuko. 2014. The Multi/plural Turn, Postcolonial Theory, and Neoliberal Multiculturalism: Complicities and Implications for Applied Linguistics. Applied Linguistics 37: 474-94. [CrossRef]

Lea, Mary R., and Brian Street. 1998. Student Writing in Higher Education: An Academic Literacies Approach. Studies in Higher Education 23: 157-72. [CrossRef]

Lee, Jerry W., and Christopher Jenks. 2016. Doing Translingual Dispositions. College Composition and Communication 68: 317.

Leonard, Rebecca L. 2014. Multilingual Writing as Rhetorical Attunement. College English 76: 227-47.

Lillis, Theresa, and Mary Jane Curry. 2006. Professional Academic Writing by Multilingual Scholars: Interactions with Literacy Brokers in the Production of English-Medium Texts. Written Communication 23: 3-35. [CrossRef]

Lillis, Theresa. 2008. Ethnography as Method, Methodology, and "Deep Theorizing": Closing the Gap between Text and Context in Academic Writing Research. Written Communication 25: 353-88. [CrossRef] 
Myers, Greg. 1990. Writing Biology: Texts in the Social Construction of Scientific Knowledge. Science and Literature. Madison: University of Wisconsin Press.

Obama, Barack. 2014. Presidential Memorandum-Creating a Federal Strategy to Promote the Health of Honey Bees and Other Pollinators. Washington: The White House.

Pollinator Health Task Force. 2015. National Strategy to Promote the Health of Honey Bees and Other Pollinators. Washington: Pollinator Health Task Force.

Readings, Bill. 1996. The University in Ruins. Cambridge: Harvard University Press.

Ruetten, Mary K. 1998. Abidjan Journal. College English 60: 51-56. [CrossRef]

Smith, Kathleen S. 1993. A Case Study on the Successful Development of an International Teaching Assistant. Innovative Higher Education 17: 149-63. [CrossRef]

Spack, Ruth. 1988. Initiating ESL Students into the Academic Discourse Community: How Far Should We Go? TESOL Quarterly 22: 29-51. [CrossRef]

Strauss, Anselm L., and Juliet M. Corbin. 1991. Basics of Qualitative Research: Grounded Theory Procedures and Techniques. Newbury Park: Sage.

Street, Brian. 2009. The Future of 'Social literacies'. In The Future of Literacy Studies. Edited by Mike Baynham and Mastin Prinsloo. London: Palgrave Macmillan UK, pp. 21-37.

Sustainable Agriculture Research and Education. 2012. Sustainable Agriculture Grants. Available online: http:/ / www.sare.org/Grants (accessed on 10 June 2017).

Tardy, Christine M. 2009. Building Genre Knowledge. Second Language Writing. West Lafayette: Parlor Press.

Urciuoli, Bonnie, and Chaise LaDousa. 2013. Language Management/Labor. Annual Review of Anthropology 42: 175-90. [CrossRef]

Weber, Max. 2015. On the Methodology of the Social Sciences. Raleigh: Lulu Press, Inc.

Weidman, John C., Darla J. Twale, and Elizabeth L. Stein. 2001. Socialization of Graduate and Professional Students in Higher Education: A Perilous Passage? Jossey-Bass in cooperation with ERIC Clearinghouse on Higher Education: San Francisco: Association for the Study of Higher Education, Graduate School of Education and Human Development, the George Washington University.

(C) 2017 by the authors. Licensee MDPI, Basel, Switzerland. This article is an open access article distributed under the terms and conditions of the Creative Commons Attribution (CC BY) license (http:/ / creativecommons.org/licenses/by/4.0/). 